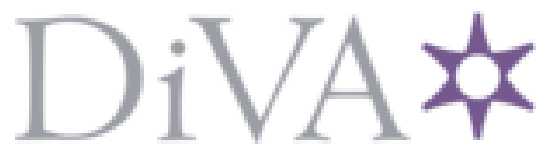

http://www.diva-portal.org

This is the published version of a paper presented at ICOLD Symposium, 9-14 June, Ottawa, Canada.

Citation for the original published paper:

Nordström, E., Malm, R., Hassanzadeh, M., Ekström, T., Janz, M. (2019)

Guideline for structural safety in cracked concrete dams

In:

N.B. When citing this work, cite the original published paper.

Permanent link to this version:

http://urn.kb.se/resolve?urn=urn:nbn:se:kth:diva-261090 


\title{
Guideline for structural safety in cracked concrete dams
}

\author{
E. Nordström, R. Malm \& M. Hassanzadeh \\ SWECO, Stockholm, Sweden
}

T. Ekström \& M. Janz

AF, Stockholm, Sweden

\begin{abstract}
Several concrete dams show cracking, and their condition and remaining service life must be determined. Assessment and service life prediction of cracked dams should include an investigation to determine the cause and consequences of cracks. Cracks can be caused by different mechanisms, which also may act together. Some mechanisms act during a short period of time, e.g. in the beginning after construction, while other mechanisms may influence the dam during the whole service-life. Therefore, it is important to combine observations, measurements, laboratory tests and theoretical analyses investigating the causes of the cracks, their future development and the influence they may have on the performance of the dam. Lessons learned and knowledge concerning crack propagation in concrete and rock, general material engineering, durability concerns caused by cracks, structural analysis issues connected to cracks, field measurements and design of remedial measures has been compiled in a Swedish guideline. The guideline highlights issues that should be looked for in inspections and contains a methodology to determine the residual strength and serviceability of cracked concrete dams and how to review dam safety criteria's. This in turn will provide the dam owner with a better means to manage and prioritize rehabilitation and maintenance work
\end{abstract}

RÉSUMÉ: De nombreux barrages en béton sont atteints de fissuration nécessitant une évaluation de leur état ainsi que de leur durée de vie. Ce travail doit inclure une étude permettant d'identifier les types ainsi que les causes de fissuration affectant l'ouvrage. Les fissures peuvent être causées par plusieurs mécanismes, pouvant dans certains cas interagir entre eux. Certains mécanismes apparaissent durant un période de temps limitée, comme au début de la phase de construction, alors que d'autres peuvent être actifs durant l'ensemble de la durée de vie de l'ouvrage. Il est en conséquence important d'associer observations, auscultation et analyses théoriques lors de l'évaluation des types de fissures et de leurs causes, de leur évolution dans le temps ainsi que des éventuelles conséquences que celles-ci peuvent exercer sur la performance future du barrage. Les connaissances ainsi que le retour d'expérience concernant la propagation de fissures dans le béton et les roches, la mécanique des matériaux, les problèmes de durabilité induits par la fissuration, le calcul scientifique, les méthodes d'auscultation et la définition de solutions de confortement ont été consignés dans un guide méthodologique suédois. Ce guide met en exergue les types de pathologies qui doivent être recherchées lors des inspections et présente également une méthodologie pour estimer la résistance et la durée de vie résiduelles de barrages présentant des fissures. Une méthode de présentation des critères de sécurité est également incluse. Ce guide permet à l'exploitant d'optimiser la gestion de l'ouvrage, notamment concernant la hiérarchisation des travaux de maintenance et de confortement. 


\section{INTRODUCTION}

The Swedish concrete dam portfolio has an average age of over 75 years. Several concrete dams suffer from cracking, and their current condition in relation to dam safety, serviceability requirements and remaining service life must be determined.

Condition assessment and service life prediction of the cracked dams should include an extensive investigation to determine the causes and consequences of cracks. Cracks can be caused by different mechanisms, which may also act together. Some mechanisms act during a short period of time, for instance in the beginning of the dam's service-life, while other mechanisms may influence the dam during the whole service-life. Therefore, it is important to combine observations, measurements, laboratory tests and theoretical analyses investigating the causes of the cracks, their future development and the influence they may have on the performance of the dam.

This paper presents the results of an assignment with the goal to develop a Swedish engineering guideline for assessment of the structural safety of cracked concrete dams. The guideline intends to increase the technical awareness among dam safety engineers and to highlight issues they should pay attention to during inspections. The work has aimed to reorganize and adopt some well-established methodologies for assessment of the residual strength and serviceability of cracked concrete dams and how to compare with dam safety criteria's. This in turn will provide the dam owner with better means to manage and prioritize rehabilitation and maintenance work.

The work has been performed in a joint project between consulting engineers from both SWECO and ÅF with financial support from the Swedish power industry via The Swedish Energy Research Centre.

\section{MANAGEMENT OF EXISTING CONCRETE DAMS}

A responsible management of existing dams should include:

I. Definition of requirements (section 2.1)

II. Condition assessment (section 3)

III. Analysis (section 4)

IV. Measures (section 5)

V. Feedback or lessons learned from performed measures (section 6)

The guideline presented here contains a description of all the above parts and this paper gives a summary. Part I is described in this section.

\subsection{Requirements}

According to the Swedish dam safety guidelines RIDAS (2017) the general requirements are formulated as:

"The prerequisites for a high dam safety level is to design and construct facilities with appropriate safety margins, operate and maintain in a safe manner and to have a preparedness to deal with arising situations"

Generally, the overall requirements for Swedish dam and hydropower facility owners with concrete dams is to assure that water is safely stored and discharged. The requirements for power production is commonly described as highest possible availability and uninterrupted electricity generation. More specific requirements for concrete structures are to:

- Be impervious to water

- Have acceptable stability and act monolithic

- Fulfill requirements on load-bearing capacity and stiffness. 
The requirements are valid in the moment the condition control is performed and commonly for a foreseeable time.

\section{CONDITION ASSESSMENT}

\subsection{Visual inspections}

Visual inspection is an important part of the surveillance and condition assessment of concrete dams. The inspections are performed with different intervals and with different requirements on formal competence. Commonly the visual inspections are performed as routine inspections (weekly), inspections (twice a year), in-depth inspections (once every three years) and as part of in-depth dam safety evaluation (once every 9 years). With a systematic, structured and informed visual inspection useful information about the condition of the dam can be collected.

The major purpose with the visual inspections is to detect changes and damages and to do a preliminary judgement of the impact on load-bearing capacity, stability and service-life from any detected deviations. A visual inspection is executed by the eye and with simple tools and without any sampling from the concrete structure to be inspected. Common deviations to look for are:

- cracks

- spalling

- delamination

- corrosion

- relative movements or settlements

- leakage

- efflorescence and deviating colors from leaching

Planning and preparations before executing a visual inspection is crucial. The preparations are recommended to start with studying existing drawings and reports from previous inspections and in addition to this also the following examples on input should be included (if available):

- year of commissioning (for capturing the concrete era used at the time of construction)

- documented changes or repairs of the dam

- requirements and functionality on different sections of the dam

- used mix-design and available reports from the time of construction

- exposure environment for different parts of the structure

During the visual inspection a recommended minimum level on equipment shall be:

- torch-light

- camera

- binoculars

- measuring tape, crack width gauge

- hammer

- screw driver

Cracks can be divided into three different categories (see Figure 1), namely cracks initiated:

I- BEFORE hardening, discovered during hardening och shortly after

II- AFTER hardening, due to chemical or physical processes and sometimes in combination with each other

III- by STRUCTURAL LOADS that exceeds the design level.

Crack mapping from a visual inspection should be documented in a proper way for future comparison to detect any changes and as a good platform for interpretation of the reason for cracks. Information like crack patterns, localization, orientation, general main dimensions 


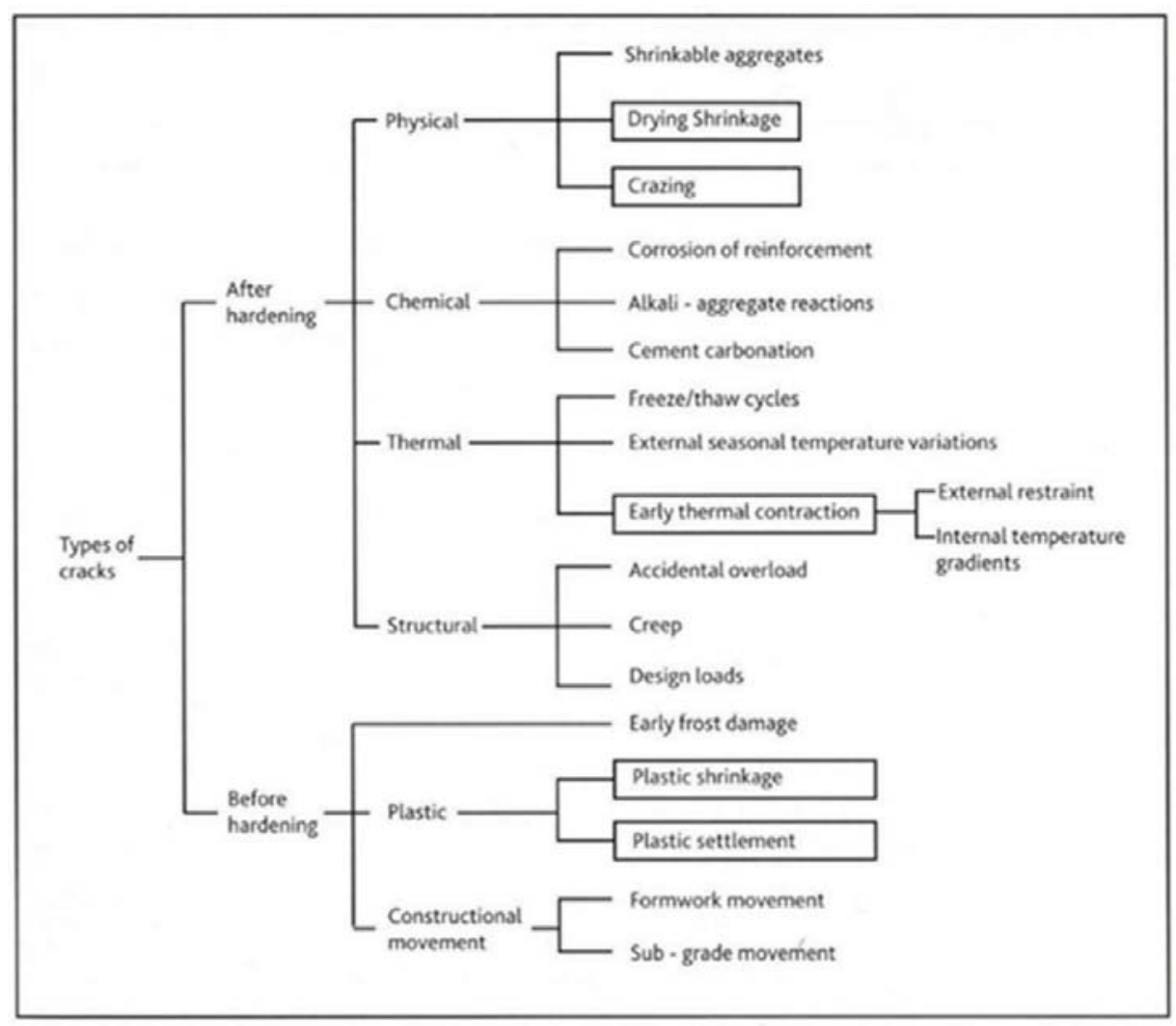

Figure 1. Common crack types according to Concrete Society (2003)

(length, width, depth). Ambient conditions with temperature and load situation (e.g. reservoir level, ice situation etc.) must also be documented. High quality photos give a good documentation and also digital photogrammetry is useful. Assistance with drones for close photos on areas not so easily accessed is an efficient tool.

\subsection{In-depth inspections}

In case of a situation where the noticed cracking is considered to be a potential problem or already stated to be a problem an in-depth inspection and investigation is needed. The purpose with the in-depth inspection is to collect more data on the actual status and to be able to analyze the current situation and future development. It will also give guidance on the level of urgency to do any repair measures. In Table 1 different reasons for an in-depth investigation and examples are shown. The content of an in-depth inspection primarily depends on the damage type, the reason for damages and the purpose of the inspection. In-depth inspections can contain core drilling for preparation of samples for different laboratory tests, installation of gauges and equipment for monitoring/measurements to survey any changes. The preparations in brief are the same as for visual inspections. In addition to that, it is recommended to develop a program that also covers additional tools and preparations for e.g. pointing out the location of samples and how the samples shall be taken.

In the presented guideline there is guidance on to identify the cause (including a brief description of the mechanism), and the type of cracks by means of visual, or together with an in-depth, inspection. The guideline also addresses the possibility for the cracks to develop with time and the parameters that are of importance to consider for further analysis. The guideline addresses a set of 16 different crack types that originates from:

1. Plastic settlement

2. Plastic shrinkage

3. Heat of hydration 
Table 1. Examples on reasons for in-depth inspections and investigation.

\begin{tabular}{|c|c|c|}
\hline No. & Reason & Example \\
\hline 1 & $\begin{array}{l}\text { Damage detected, reason for cracking not } \\
\text { known or has to be verified }\end{array}$ & $\begin{array}{l}\text { - Cracking caused by frost action and/or ASR. } \\
\text { - Cracks originating from settlements, restraint } \\
\text { (internal/external) or other types of attack. }\end{array}$ \\
\hline 2 & $\begin{array}{l}\text { Damage reason/-process known, but current } \\
\text { status/speed of development not known }\end{array}$ & $\begin{array}{l}\text { - Carbonation and/or chloride ingress in concrete } \\
\text { cover with risk for reinforcement corrosion. } \\
\text { - Expansion from ASR. Residual expansion poten- } \\
\text { tial not known. } \\
\text { - Extent of frost action and future development } \\
\text { - Leaching of concrete cover. Leaching in cracks. } \\
\text { - Crack stability or propagation with time. }\end{array}$ \\
\hline 3 & Consequences from damage & $\begin{array}{l}\text { - Impact on stability or load-bearing capacity. } \\
\text { - Influence on water-tightness } \\
\text { - Effect on durability }\end{array}$ \\
\hline 4 & Quality control, monitoring and follow up & $\begin{array}{l}\text { - Controlling effect from preventive or repair } \\
\text { measures }\end{array}$ \\
\hline
\end{tabular}

4. Autogenous shrinkage

5. Seasonal variations (in temperature)

6. Drying shrinkage

7. Shrinkage from carbonation

8. Map cracking at formwork surface and steel troweled surface

9. Reinforcement corrosion

10. Alkali-silica-reactions

11. Frost-action

12. Sulphate attack

13. External loads - short term

14. External loads - permanent

15. Dynamic loads

16. Imposed deformations

\subsection{Sampling and laboratory investigations}

The awareness about the purpose of sampling of the one who performs the sampling is crucial to obtain good quality concrete samples for any type of laboratory investigation. Especially visual inspection of cores must be made systematically to evaluate general quality, crack frequency and crack planes inside the concrete and any signs of degradation. After core drilling the hole in the concrete structure can be used for bore-hole imaging and water-permeation tests to get more information.

\subsection{Measurements and laboratory investigations}

This section gives concrete guidance and tools on how to perform measurements of importance for detection and/or assessment of different mechanisms causing the cracks. Parameters and tools for measuring e.g. temperature and humidity, crack widths, freeze-thaw testing, residual expansion tests are described. Also, more advanced measurements like e.g. thin sections for micro structural analysis, petrographic analysis, air pore system analysis with plane sections along with their advantages/disadvantages and limitations are generally described. Field methods to follow expansion like e.g. LCPC-cracking-index method (LCPC, 1997) $(\mathrm{LCPC}=$ Laboratoire Central des Ponts des Chaussées) is described (see Figure 2 below) 


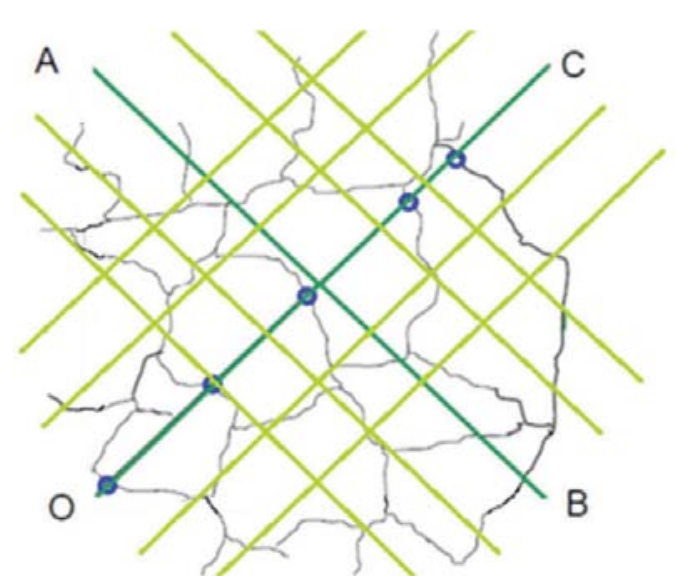

Figure 2. LCPC-cracking index method (LCPC, 1997)

where the crack widths are summarized in a systematic way on a designated surface. This makes it easier to follow up any expansion in future inspections.

\section{ANALYSES}

Regardless of what type of analysis that is performed, a model must be created. The model should in its simplest form give a picture of the structural way of action and thereby be a platform for assumptions and simplifications in the analysis. A model can be on different levels from the conceptual model, via an equation based analytical models to more advanced finite element models. The purpose of the analysis is usually to determine the cause of the damage and then to estimate the bearing capacity and stability. To determine the cause of the damage, the actual load history should be used. To estimate the load bearing capacity and stability, the design loads from guidelines or codes shall be used. The guideline presents different analyze models and their suitability for evaluating the impact of cracks or to define the crack reason on a concrete structure.

\subsection{Analysis methods}

\subsubsection{Conceptual models}

The basic conceptual model is set up to give an understanding of the structural way of action since this is of importance for the decision on e.g. how large part of the dam that must be taken into consideration in the analysis. It also has an impact on the boundary conditions and how the loads shall be applied etc. The conceptual model should include a hypothesis on the reason for observed damages and the mechanisms behind since this will be an important input for the following calculations. Involvement of the designated reviewer already in this stage is crucial since any improper assumptions in the conceptual model has a major impact on the validity and the conclusions from the following calculations. A conceptual model is often created in a discussion on site during an inspection together with personnel from the Owner.

\subsubsection{Analytical calculations}

If the analyzed structure can be considered as a simple structural member, i.e. a separate element, with well-defined boundary and initial conditions exposed to simple mechanical (e.g. bending) or environmental load (one-dimensional transport), analytical calculations can be sufficiently accurate and cost effective to evaluate a cracked structure. The models should be conservative. Some examples on situations are:

- Stability calculations (global/local, probabilistic analysis etc.)

- Load bearing capacity (stage I-III, modified compression field theory, strip-method etc.) 
- Behavior models (multiple linear regressions analysis in prediction of monitoring data etc.)

- Degradation models (1D-models for e.g. leaching)

- Dynamic mass-spring systems (1D-models)

Most analyses are based on a deterministic model where loads and material properties are chosen to correspond to a real response or limit states like e.g. service- or ultimate limit state or stability analysis. Analytical calculations are often combined with more advanced calculations e.g. for more complex cases where calculations performed with finite element methods are used to extract cross sectional forces to be used in analytical calculations in e.g. reinforcement design. Analytical calculations should also always be used for verifying the results from an advanced calculation.

\subsubsection{Finite element calculations}

The complexity of the geometry and different physical impacts of real structures often makes simple analytical calculations very rough. Then finite element calculations are often more suitable. A majority of the numerical simulations are based on the finite element method with assumption of a linear response of the structure and the material. That is also a prerequisite for superimposing of loads. The method is general and can be applied to create any geometry, load cases etc. that can be discretized in a number of elements. Some examples on applications are:

- Stability calculations (global/local)

- Deformations and load bearing capacity (e.g. frame analysis)

- Reinforcement measures (post-tensioned anchors, overlays etc.)

- Simulation of construction phases (pouring sequence, demolition, reconstruction)

- Evaluation of dam monitoring

\subsubsection{Non-linear finite element calculations}

Non-linear analyses simulate a complex structural behavior where synergy between different effects give that superimposition is no longer possible. A number of reasons can give a nonlinear behavior, e.g. non-linear

- Contact or boundary conditions (behavior depending on load or load level)

- Material behavior (properties change with time, load etc.)

- Geometrical conditions (large deformations or initial imperfections changing stiffness)

For these cases the load history is of major importance and the order of load application can give different response. A couple of examples where non-linear calculations can be applied is:

- Stability calculations (global/local). Risk for material failure and combined failure modes.

- Deformations and load bearing capacity

- Reinforcement measures (post-tensioned anchors, overlays etc.) incl. initial imperfections

- Simulation of construction phase (pouring sequence, demolition) incl. early age concrete

- Evaluation of dam monitoring for a damaged structure with e.g. cracks.

\subsection{Selection of method}

The choice of analysis methods depends on the purpose with the calculation. It is often the required level of detail in the results that give how advanced methods shall be used. In spite of this, it is important to emphasize that a more advanced model not automatically give a better result. The guideline includes a table with suitability for different methods depending on the purpose with the calculation. 


\subsection{Simulation of different phenomena}

To estimate the condition of a cracked structure, its safety against failure and potential need for measures the initial conditions and any noticed vulnerabilities must be considered. The presented guideline gives a description of typical detrimental phenomena for concrete dams and how they should be incorporated in an analysis with numerical methods. The phenomena described are:

- Early age concrete (heat of hydration, development of properties etc.)

- Long-term effects (creep, relaxation, shrinkage

- Cracking of concrete (interaction with reinforcement, non-linear behavior)

- Degradation of concrete (ASR, frost action, corrosion)

- Seasonal temperature variations (steady state, transient)

- Simulation of measures (overlays, post-tensioned anchors)

- Stability (sliding, overturning, combinations of both)

\subsection{Modelling aspects}

\subsubsection{Material models}

To simulate cracking and crushing of concrete there are a number of different constitutive material models to choose between. Common for all material models are that they are based on fracture mechanics, plasticity theory and/or damage mechanics to describe the reduction of the material stiffness due to cracking. There are two major models to describe the cracking of concrete, namely the smeared crack model or the discrete crack model. Basically, the difference is that the cracks are distributed over the element in the smeared crack model and with the discrete crack model there will be a crack between the elements (in an interface element).

In the guideline, recent results from the ICOLD Benchmark workshop on numerical analysis of dams are implemented (Malm et al, 2017). One case consisted of a cracked arch dam and in the 16 contributions the following material models where used:

- Fracture mechanical (fix or rotating cracks)

- Damage based models (only isotropic)

- Combinations of plasticity theory and damage mechanical (only isotropic)

- Combinations of plasticity theory and failure mechanics

The results showed that all types of material models could predict cracking with sufficient accuracy. However, simplified models with only uni-axial behavior and elasto-plastic behavior did not predict the cracking and deformations in a good way.

\subsubsection{Limitations}

Defining limitations or simplifications in the numerical model is needed so that only relevant parts of the structure and the load effects or behaviors is simulated. A common simplification in stability analysis is e.g. that the dam body is considered to be monolithic. A limitation in the model can also be to choose between modelling the materials in linear elastic conditions or if non-linear effects should be included. Geometrical nonlinearity is rarely a problem for dams. Limiting the size of the model via e.g. symmetrical conditions or amount of foundation included is beneficial to limit the calculation time. Using the fact that e.g. long buttress dams are divided with dilatation joints can limit the model size with the assumption that as long as the deformations are not too large, the monoliths can move independently. It is important to keep the conceptual model in mind and consider the impact from any limitations of simplifications in the interpretation of the results.

\subsubsection{Boundary conditions, interactions and contact formulations}

Boundary conditions are defined in a model by prescribing an expected behavior along the boundaries of the model and they can have large impact on the response from the model. 
Therefore, they must reflect the real behavior as far as possible. Knowledge of the effect from different boundary conditions on the used element types is also crucial.

For concrete dams, the model size of the foundation and how the boundary conditions are applied on this is of importance. Influence on the temperature conditions in the bedrock close to the dam should be considered. Due to geometry, solid elements are often used for modelling of dams and the number of boundary conditions or loads applied in single nodes should therefore be limited and instead applied over surfaces.

Large concrete dams have a large heat capacity and Swedish dams are often insulated (and sometimes heated) which gives further increased total heat capacity. In simulations with ambient temperatures this must be considered with transient temperature analysis and that boundary conditions are defined with a transition resistance (robin boundary conditions).

\subsubsection{Crack propagation, existing cracks or damages}

Cracks in concrete dams are not uncommon. Some cracks have no influence on the global behavior and some will influence the potential failure modes. Significant cracks, especially all throughcracks, must be considered in the analysis. In stability calculations any existing major crack must be considered as a risk for internal failure modes with non-monolithic failure. In Figure 3 an example is given for a buttress dam with an inclined all through crack in the supporting buttress. Seasonal thermal variations is the reason for the crack. This could give propagation of the crack followed by a partial overturning failure of the buttress.

In finite element calculations it is easy to include cracks. Large number of cracks and cracks intersecting each other can give problems to perform the analysis due to all contact iterations. The concrete surrounding discrete cracks is considered linear elastic and the user must control that the allowed stress or strain levels not are exceeded if the intact concrete is considered as linear elastic. Another option is to use non-linear constitutive material models to simulate the crack propagation which can be useful to find out the reason for cracking.

\subsection{Material data}

Used material data should at firsthand be based on measured properties on the studied dam. Because the tensile strength is so important in cracking, it is important to test it. Without testing the properties must be estimated from codes like Eurocode 2 (2008) or Model Code 2010 (2010). In simple analytical stability calculations, gravity of concrete and the friction between concrete and the foundation are needed as input. More advanced simulations also need data like:

- E-modulus (also in linear elastic FE-calculations)

- Poissons ratio (also in linear elastic FE-calculations)

- Compressive and tensile strength

- Fracture energy

- Shape of working curve from uniaxial compressive test

- Load-bearing capacity in shear for cracked concrete

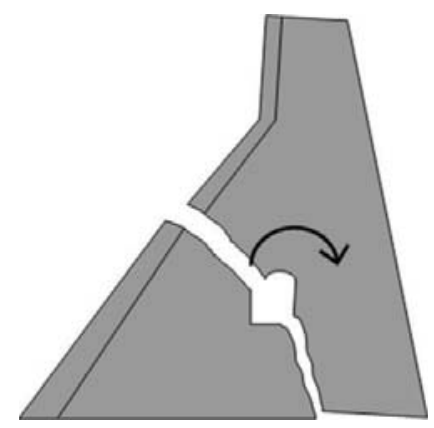

Figure 3. Buttress with non-monolithic overturning failure 
- Relation between uni-, bi- or triaxial- loadbearing capacity

- Heat and strength development, creep etc. (early age concrete)

The variation or uncertainty of material parameters has limited impact on linear elastic calculations but to a large extent in non-linear calculations. For non-linear calculations especially working curves in tension is seldom given in codes. One suggestion is given in Figure 4 below.

Selection of fracture energy and characteristic length must be done taking to account the commonly larger aggregates used in dam concrete and guidance can be found in Brühwiler (1990) and Ghaemmaghami and Ghaemian, (2006).

\subsection{Validation of model}

All numerical models must be validated. The complexity of the model and if the engineer is used to the application are parameters that give how detailed the validation must be. To validate a calculation model, several steps must be taken. According to Model Code 2010 (2010) a validation should contain validation of:

- Material model

- Structural model

- Convergence

Simple models based on conventional, standard, procedures are validated primarily on the selection of input data (parameters, loads etc.) and suitability in the selection of method/ model for the specific application. Validation can be made e.g. via parametric sensibility studies.

More advanced e.g. self-developed material models, new models to the user or complicated structures alternatively advance simulation of phenomena's can need a more thorough validation. This can be made e.g. with comparative measurements and/or analysis of documented standard cases from the literature. The resulting calculated crack pattern, or area with high stresses, can advantageously be compared to the actual appearance of the real dam

\subsection{Modelling the impact of a crack}

The reinforcement is activated when concrete cracks, but cracks give reduced stiffness and larger deformations under applied loads. That can give new potential failure modes apart from durability problems. An analysis can give that the dam, in spite of the cracks, fulfil the requirements but also that further analysis is needed to assure the dam safety level. In Figure 5 a flow chart is given to visualize how to find out the appropriate level of complexity in the analysis.

\subsection{Acceptance criteria}

It is complicated to estimate if the dam is safe or not in the assessment of results from modelling. Uncertainties in input data and prerequisites, but also since the failure behavior can be
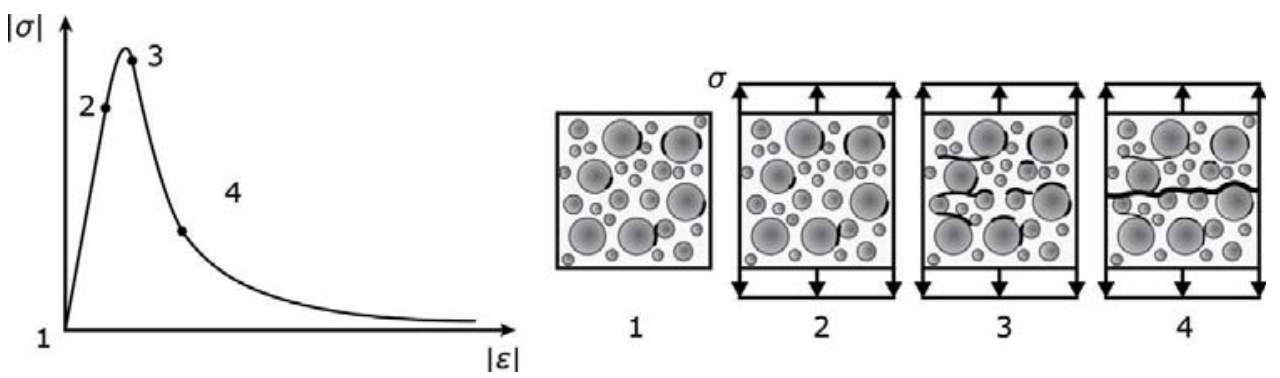

Figure 4. Working curve and illustration of cracking in tension (Nordström et al, 2019). 


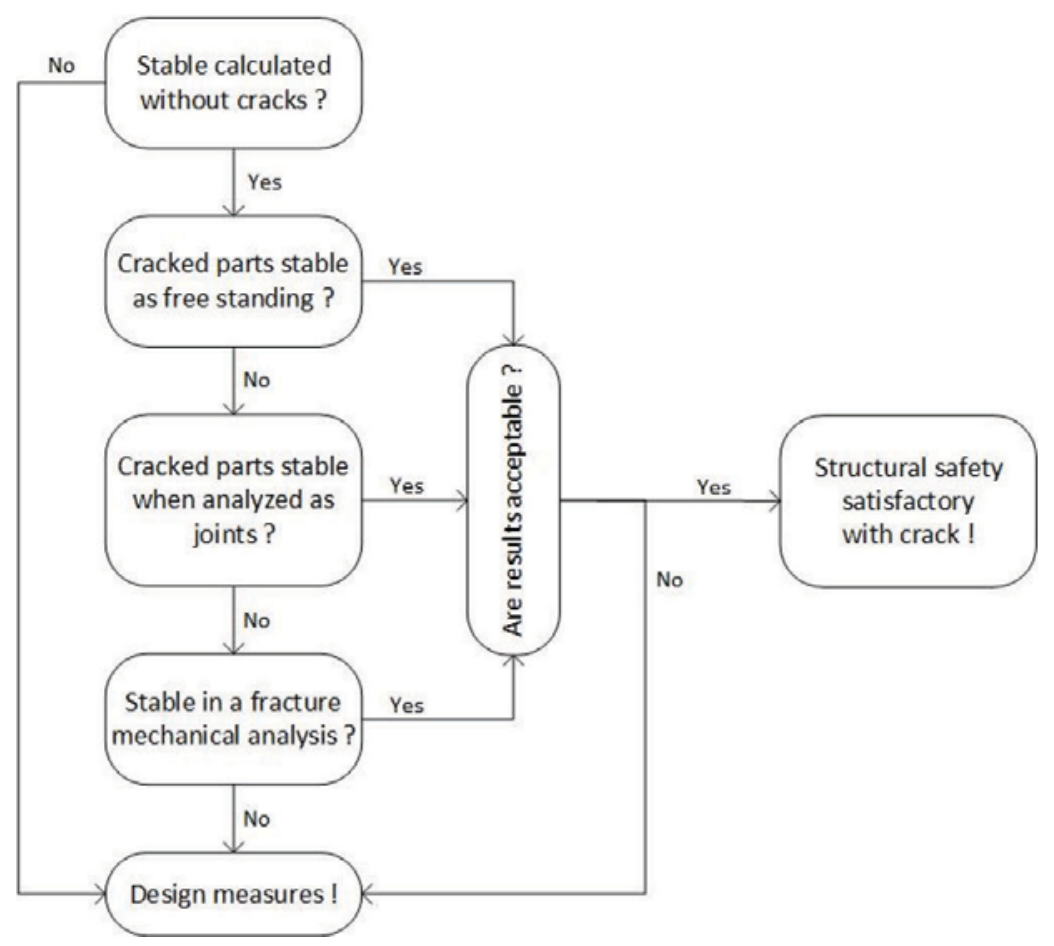

Figure 5. Flow chart for modelling the impact of a crack (after Westberg Wilde et al, 2016).

highly non-linear and thereby difficult to predict if the structure is considered acting linear elastically. It is reasonable that special acceptance criteria should be developed for existing, cracked structures and this area needs further development. Generally, the degree of conservatism should be larger the simpler model that is used. The definition of a failure is commonly divided in service-life state or ultimate-limit state.

\section{MEASURES}

When the condition control and following analyses show that the requirements on a concrete dam are not fulfilled with existing cracks measures has to be taken. Measures must be designed to make the structure reach the required level or to minimize the risk for being lower than that. The current section presents different solutions to deal with cracks in an existing concrete dam.

\subsection{Emergency measures}

Extensive cracking very seldom occurs instantly on concrete dams but rather during a long time-period. In spite of this it can occur, and a recent example of at least suddenly noticed major crack is at the Wanapum Dam in the US (Hunter, 2016). The event started when the operational staff noticed that the bridge deck and the bridge railing were deformed. A large horizontal crack ( $\sim 50 \mathrm{~mm}$ in width) in an upstream construction joint was the detected with divers.

To lower the risk for a stability problem and failure of the dam it was concluded that a draw-down of the reservoir with around $9 \mathrm{~m}$ would give a sufficient safety margin while further examining the reason for the crack and how to resolve the problem.

The event and immediate measures must be considered as emergency measures to quickly lower the risk of a dam failure. Other emergency options could have been fully loaded trucks on the crest and if there would have been leakages, temporary sealing with coal dust or saw dust etc. could have reduced the leakage. Sealing with sheets like tarpaulins is another possible 
option for temporary leakage reduction. All temporary emergency measures are best planned in advance in an emergency preparedness plan so that access to material or coordinates to contractors to contact quickly is already on the table. Information on bridge deck load-bearing capacity and alternative access roads should also be clarified in the plan.

\subsection{Monitoring}

The results from an initial analysis of the impact from the cracking can sometimes lead to the conclusion that the cracking today, or in the nearest future, is not considered to be a direct threat to the safety or the load-bearing capacity. Instead there might be a need for better basis to evaluate the actual status by trying to define if the cracking is static (constant) or dynamic (propagating). A monitoring campaign can then be a good option to state the condition and to get more info on the reason for a potential crack propagation. If the crack is of a propagating type also the reason for this must be defined and what parameters giving the propagation (concrete expansion, insufficient load-bearing capacity, seasonal temperature differences, reservoir load, ice load etc.)

The basis for design of a monitoring system on a concrete structure is the understanding of its structural way of action. This is crucial to understand the impact of occurring cracks and how to, and where to, monitor them. If the cracking is extensive, numerical modelling can be an efficient tool to study the behavior and to define where any early signs of movements will be detected first.

If the monitoring system is supposed to be part of the permanent surveillance on the dam, potential threats and failure modes together with the consequence in case of failure should be taken into account in the design. Most commonly cracks have an impact on the cross-sectional load bearing capacity either due to the crack itself or due to any ongoing degradation process in connection to the crack. Less likely, but still possible like in Wanapum described above, is that a stability problem via partial progressive overturning leads to a dam failure.

The equipment to detect crack movements should be selected carefully and always be combined with temperature measurements to take thermal movements into consideration in the evaluation. Preferably temperature in the concrete, ambient air temperature and the water temperature. If the cracking is suspected to have an impact on the global behavior of the dam, especially for high buttress dams, it is efficient to install gauges to monitor the crest movement with pendulums. Other obvious criteria for selection of gauges is that they should be adapted for the exposure environment, be calibrated and easy to calibrate in the future, have sufficient accuracy and resolution, have a range covering the expected movement.

Long dams might show a need for optimization to reduce the cost for extensive installations of monitoring equipment with remained dam safety level. Recommendations on how to do this can be found in Nordström et al. (2015).

\subsection{Diminishing measures}

Different types of measures can be used to diminish the propagation via delaying or slowing down the process causing cracking or to reduce the consequences from the cracking on e.g. durability of the structure. The primary purpose with diminishing measures are commonly either surface protection (minimize the entrainment of substances driving the degradation e.g. $\mathrm{H}_{2} \mathrm{O}, \mathrm{CO}_{2}, \mathrm{Cl}^{-}$) or climate protection (minimize the effect of ambient conditions from precipitation, thermal variations etc.).

Surface protections are, according to the European standard EN 1504 (2004), divided in the three types hydrophobic impregnation, impregnation and surface coating (se Figure 6). The first two types are based on that the protecting substance is penetrating into the concrete surface or cracks giving a protection towards ingress. In an old concrete structure, the existing humidity content prevents a deep penetration of the impregnation which can give a limited effect. The time for exposure of the impregnation product (commonly silane or siloxane) is essential to have a good penetration and often the product is applied as a gel. 


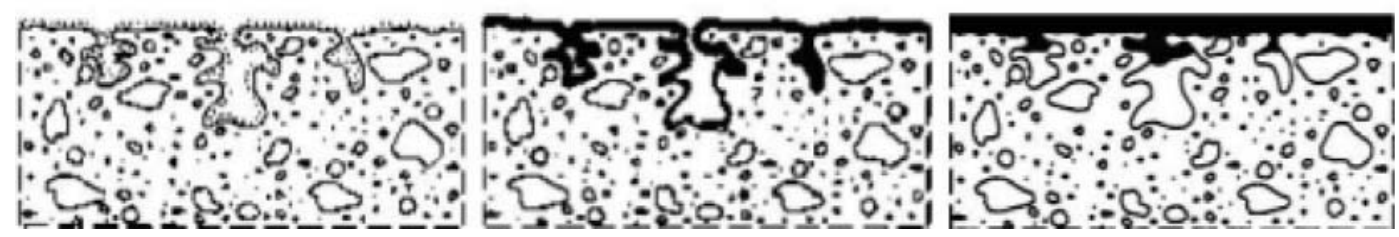

Figure 6. (1) Hydrophobic impregnation. (2) Impregnation. (3) Coating (EN 1504, 2004)

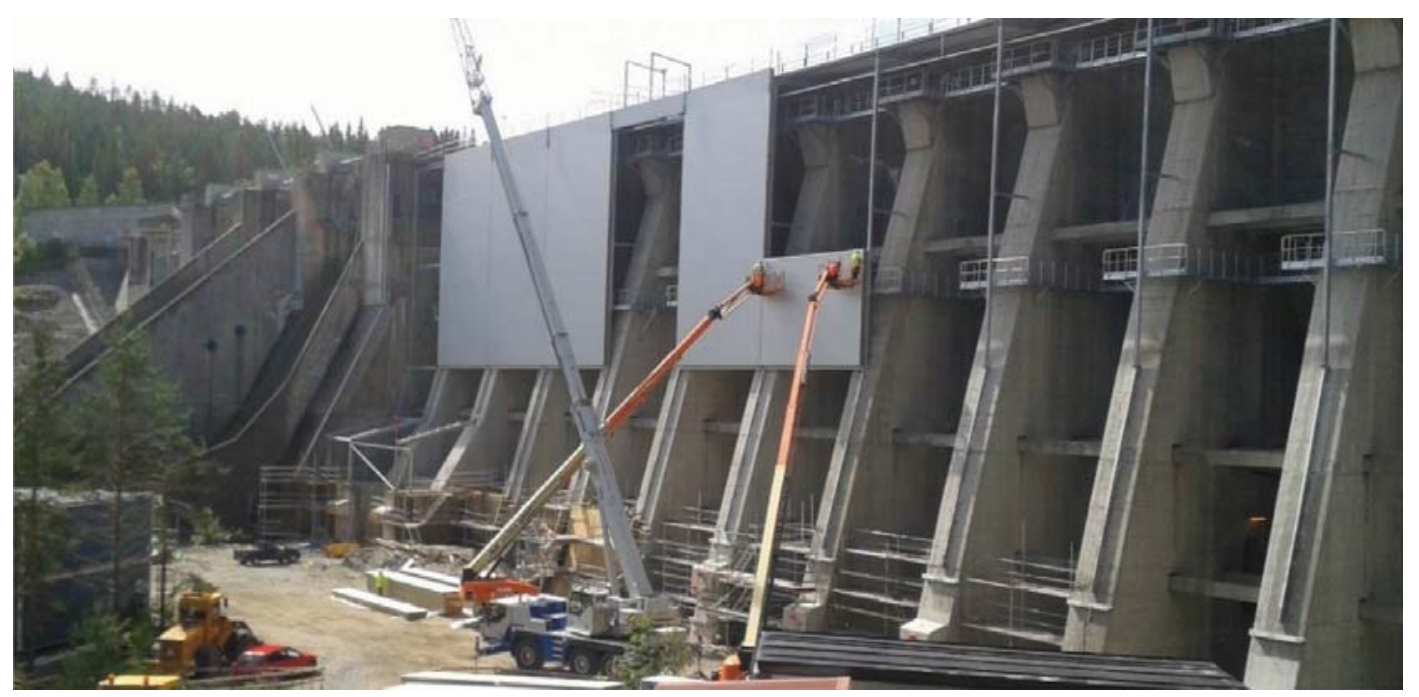

Figure 7. Mounting of climate wall to minimize thermal movements on a dam (Nordström et al, 2019)

Coatings can be of polymer type or cement based and the products primarily give a mechanical protection against ingress of detrimental substances. Climate protection to prevent further crack propagation originating from thermal movements on e.g. a buttress dam can be effective. An example is shown in Figure 7 above.

\subsection{Repair and strengthening}

Before designing a repair of a cracked concrete structure, the purpose with the repair, the expected service-life of the repair measure and the structure itself, has to be defined. The selection of method should also be done in terms of expected risk reduction. The guideline covers a brief description of the methods:

- Sealing (complete/partial cover of e.g. a front-plate or single cracks with Carpi membrane)

- Crack sealing (epoxy, polyurethane or cement-based grouting, crystallization)

- Drill-and-plug technique (concrete or mortar plugs transferring some shear force)

- Expand-seal-technique (bitumen, polyurethane etc.)

- Dry-packing of wide cracks (low w/c-ratio cement mortar or paste

- Structural reinforcement (reinforced concrete overlays, post-tensioned anchors, fibre reinforced composites)

\section{CASE-STUDIES}

Application of the methodology presented in section 3-5 is exemplified with fifteen case studies in this section. The selected cases show the steps from observation of cracks, analysis of the 
reason, the effect on the structure, comparison with monitoring and finally suggested measures. The purpose with the lessons-learned process in looking at case studies is to look back on previously performed measures to evaluate the effect both directly after execution and after time. Especially the performance with time is of major importance.

The guideline presents twelve Swedish cases with cracked dams and the process on how the dam was investigated and what measures (if any) was taken to resolve any dam safety or durability problems. In the following one of the examples is summarized.

\subsection{Swedish spillway dam with cracks}

The spillway dam, situated in the northern part of Sweden, is part of a $330 \mathrm{~m}$ long dam with an embankment dam, a power house, a short buttress dam and the spillway dam itself. The total height is about 13,5 m and the dam was commissioned in 1975. In Figure 8 below a view of the dam from downstream and the crack pattern on right hand side of pier 2 is shown.

\subsection{Field investigations}

A visual inspection was performed in 2008 and the crack pattern showed in Figure 8 was noticed. During the field investigation also testing of the carbonation depth in the concrete was done giving a depth of $30 \mathrm{~mm}$ which is about $60 \%$ of the concrete cover. Taking into consideration that the dam was about 30 years at the time for measurement the whole cover will not be carbonated in several decades. Due to the observed cracks a potential failure mode could be that the pier can fail in a partial overturning or sliding failure.

\subsection{Analyses}

A phenomenological model gave that seasonal temperature variations could have given movements and following cracks. Some of the cracks can possibly also have occurred at the time of construction since especially pier 2 was constructed in harsh conditions during winter time.

A non-linear finite element analysis (FEM) was performed with COMSOL (2012) where concrete gravity, hydrostatic water pressure on the structure and gate and variations in ambient temperatures was taken into consideration for both the pier and the connected skiboard. The analysis simulated 8 years of seasonal variations. The results gave that low temperatures during winter time could be the reason for cracking and test with applying an ice-load of 200 $\mathrm{kN} / \mathrm{m}$ (applied $20 \mathrm{~cm}$ below the maximum retention level) or exceedance of the retention level gave a minimal influence on the strain situation in the pier. The applied ice-load is in accordance with the Swedish dam safety guideline RIDAS (2017). Thereby it was concluded that the
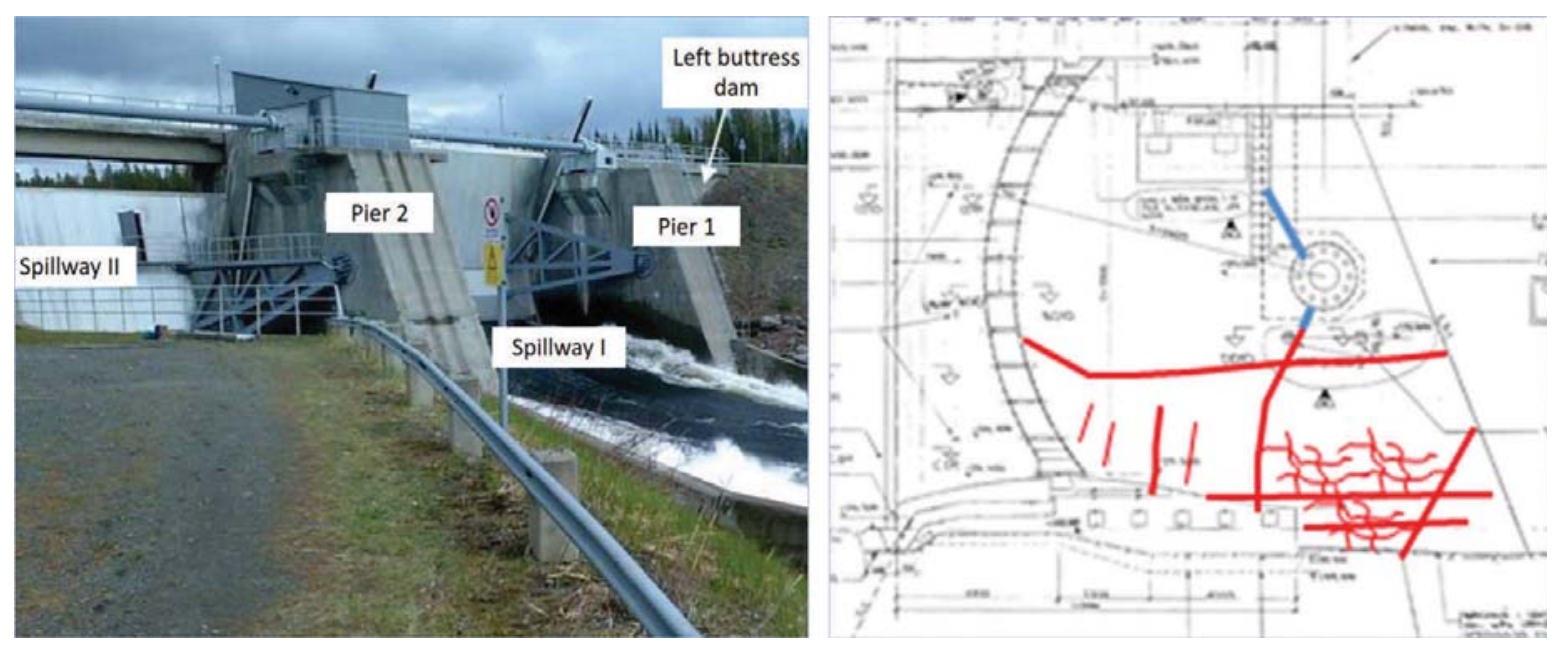

Figure 8. Overview of a Swedish spillway dam with cracks (Nordström et al, 2019) 

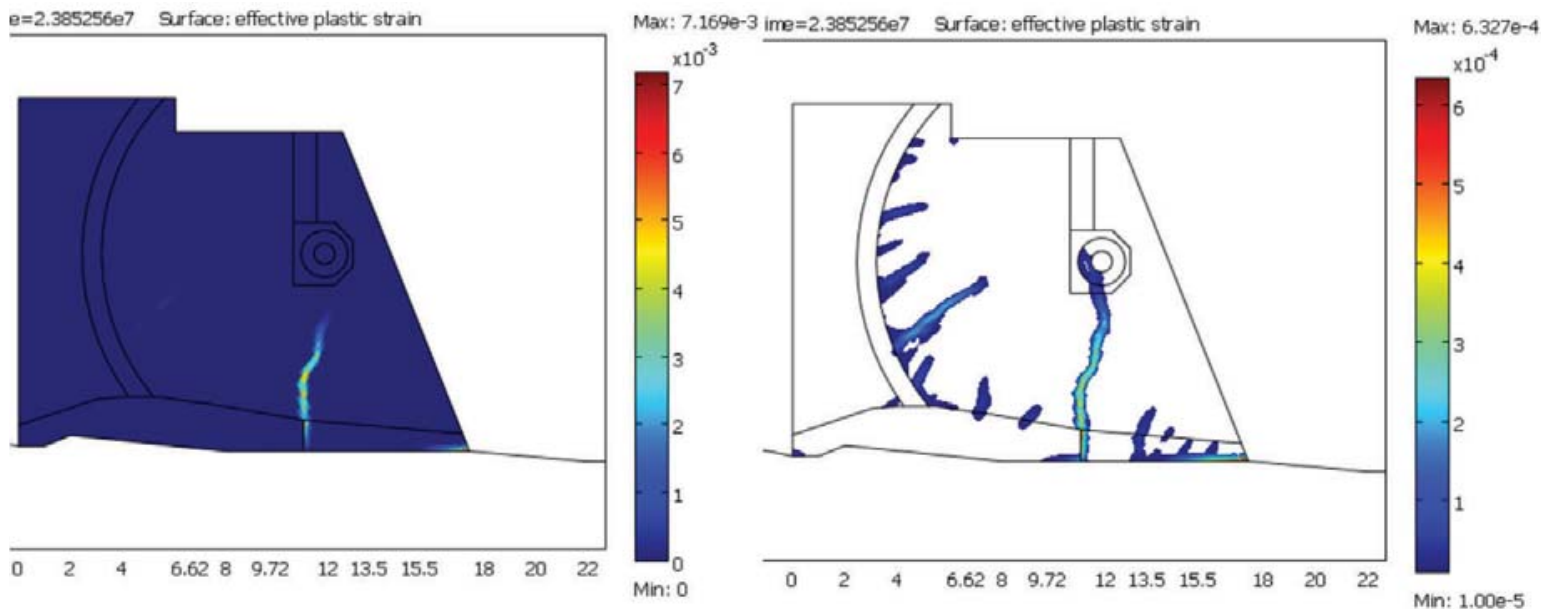

Figure 9. Calculated plastic strains and crack patterns in pier 2 (Nordström et al, 2019)

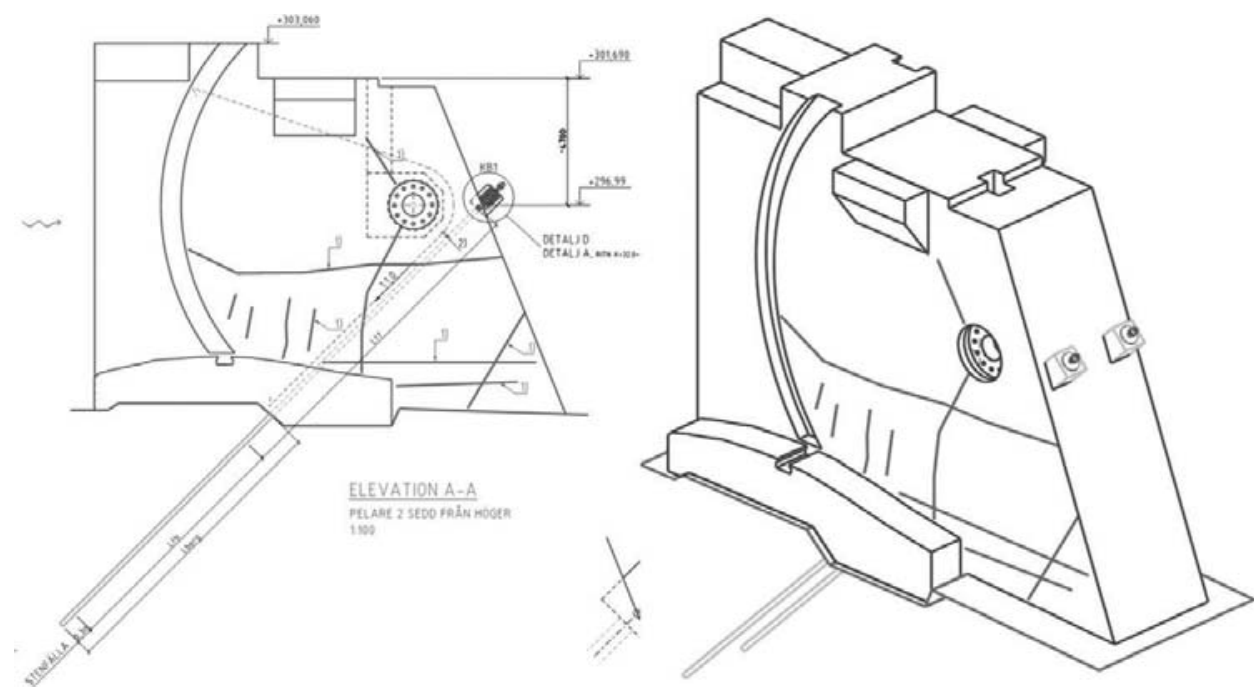

Figure 10. Pier 2 reinforced with post-tensioned anchors. (Nordström et al, 2019)

cracks were mainly caused by thermal variations. Figure 9 shows the resulting crack pattern from the simulation.

\subsection{Measures}

The cracks were considered as a risk for non-monolithic stability problems and measures had to be taken. The central pier 2 carry load from both spillway gates and therefore reinforced with two post-tensioned cable anchors. The cables secured both the vertical crack up to the gate bearing and the horizontal crack below that (Figure 10). Anchors shall be tested every 6 years to check the status and cracks shall be visually inspected at every in-depth-inspection (every 9 years).

\section{REFERENCES}

Brühwiler E. (1990). Fracture of mass concrete under simulated seismic ac-tion. Dam Engineering Vol 1, issue 3, pp 153-176.

COMSOL (2012) COMSOL Multiphysics, www.comsol.com, Sweden. 
Concrete Repair Manual, (2003), Second edition, volume 1, Published jointly by: ACI international, BRE, International concrete repair institute and concrete society.

Nordström, E., Hassanzadeh, M., Malm, R., Ekström,T. \& Janz, M. (2019). Strukturell säkerhet hos spruckna betongdammar. Energiforsk report (In Swedish, to be published).

EN 1504 (2004). Products and systems for the protection and repair of concrete structures - Definitions, requirements, quality control and evaluation of conformity. European standard.

Eurocode 2 (2008). Design of concrete structures. Part 1-1: General rules and rules for buildings. SS EN 1992-1-1:2005, SIS

Ghaemmaghami A. \& Ghaemian, M. (2006). Large-scale testing on specific fracture energy determination of dam concrete. International Journal of Frac-ture, Vol. 141 (1), pp. 247-254.

Hunter, I., et al. (2016). Repairing Spillway Damage at Wanapum Dam. http://www.hydroworld.com/art icles/hr/print/volume-35/issue-7/cover-story/repairing-spillway-damage-at-wanapum-dam.html.

LCPC Techniques et méthodes, (1997). Détermination de l'indice de fissuration d'un parement de béton. Methode d'essai LPC No. 47, Ministére de l'Équipement, du Logement, des Transports et du Tourisme.

Malm, R., Hassanzadeh, M. \& Hellgren, R. (2017). Proceedings of the 14th ICOLD International Benchmark Workshop on Numerical Analysis of Dams. KTH Civil and Architectural Engneering, report no. TRITA-ABE-RPT-1802001.

Nordström, E., Malm, R., Blomdahl, J., Tornberg, R., \& Nilsson, C-O. (2015). Optimization of dam monitoring for long concrete buttress dams. Proceedings from ICOLD annual meeting 2015, Stavanger, Norway.

RIDAS (2017). Swedish Hydropower company guidelines for dam safety. Swedenergy. (In Swedish)

Westberg Wilde, M., Janz, M., Ekström, T. (2016), Sprickors påverkan på betongdammars säkerhet., Rapport 2016:310, Energiforsk, www.energiforsk.se (in Swedish) 